\title{
The influence of parenting on maladaptive cognitive schema: a cross-sectional research on a group of adults
}

\author{
Monica Pellerone' \\ Calogero lacolino' \\ Giuseppe Mannino² \\ Ivan Formica ${ }^{3}$ \\ Simona Maria Zabbara' \\ 'Faculty of Human and Social Sciences, \\ "Kore" University of Enna, Enna, Sicily, \\ Italy; ${ }^{2}$ Department of Jurisprudence, \\ "LUMSA" University, Rome, \\ Italy; ${ }^{3}$ Department of Cognitive, \\ Psychological, Pedagogical Sciences \\ and Cultural Studies, University of \\ Study of Messina, Messina, Sicily, Italy
}

This article was published in the following Dove Press journal:

Psychology Research and Behavior Management

I February 2017

Number of times this article has been viewed

Background: The literature emphasizes the role of early interpersonal experiences in the development of cognitive vulnerability; in particular, interruptions in early family relationships, parental unavailability and dysfunctional parenting are potential evolutionary precursors to negative cognitive style and emotional disorders.

Materials and methods: This study measured the relationship of retrospective ratings on parental bonding with cognitive patterns in a group of Italian adults. The objectives of this study were as follows: to analyze the influence of age and education level on cognitive domains; to verify whether being parents and living at home with parents affect both parenting style and cognitive domains; to investigate how the type of the maternal and paternal parenting independently affects cognitive styles; to measure the predictive variables for the use of cognitive dysfunctional patterns and to investigate age as a moderating variable of the relation between parenting styles and cognitive domains in a group of adult men and women. The research involved 209 adults (118 males and 91 females) living in Sicily (Italy) aged between 20 and 60 years $(M=37.52$; $\mathrm{SD}=11.42$ ). The research lasted for 1 year. The instruments used were the Parental Bonding Instrument to measure the perception of parenting during childhood and the Young Schema Questionnaire-3 to investigate cognitive patterns.

Results: Data show that being a younger adult male with mother's parenting style characterized by a lower level of nurturance is predictive of the disconnection and rejection domain, whereas, being a younger adult woman, with a higher level of maternal control is predictive of the impaired limits domain.

Conclusion: This study underlines that because mothers and fathers establish different bonds with their children, care and control by both parents might impact different domains of development.

Keywords: parenting, maladaptive cognitive domains, behavioral strategies, emotional responses

\section{Introduction}

The cognitive model assesses the beliefs and schemes that define emotional response and individual behavioral strategies, ${ }^{1}$ beliefs or schemes are cognitive representations of personal experiences; sometimes, these events can bring maladaptive thoughts, ${ }^{2}$ dissociated emotions ${ }^{3,4}$ and maladaptive behaviors. ${ }^{5}$ Such a model is founded upon the presupposition that the external stimuli, connected to an individual elaboration of their meaning, stimulate a physiological and emotional response. In turn, these emotions have a reciprocal effect upon the cognitive content, determining maladaptive thoughts. ${ }^{6,7}$ The schemes represent one's own attitudes and beliefs; they are the fundamental tasks and the unmentioned rules, deputized for the decoding and evaluation

Correspondence: Monica Pellerone Faculty of Human and Social Sciences, "Kore" University of Enna, Via Cittadella Universitaria s.n.c, Enna 94100 , Sicily, Italy Tel +39329432 43II

Email monica.pellerone@unikore.it 
of information coming from the external world. ${ }^{8,9}$ Therefore, cognitive schemes, related to the safety, the vulnerability to threat, the evaluation of oneself as agreeable subjects, those of capacity or of effectiveness, contain basic rules for the behavior, ${ }^{10}$ which are particularly remarkable for the comprehension of anxiety, depression and personality disorders. ${ }^{11,12}$

In particular, according to the Young et al's ${ }^{13}$ model, the early maladaptive schemes seem to affect the individual's cognitions and perceptions regardless of the presence of any stressful life event. So, if individuals become aware of new information, which is inconsistent with personal core beliefs, then the individual's cognitive processing will be biased; these cognitive distortions help individuals to correct for inconsistencies between schemas and actual experiences. So, an early schema is the deepest level of cognition that contains memories and intense emotions; for these reasons, the early maladaptive cognitive schemas seem to represent vulnerability factors for psychopathology; in particular, during adulthood, when these schemas are activated by interpersonal or stressful events, individuals could develop a negative view of self and the event and cognitively distort relevant information, which may lead them to experience depression or anxiety. Confirming this, Beck ${ }^{14}$ underlines that dysfunctional cognitive styles such as magnification and overgeneralization, with negative views of self, others and the future, are significant components of depressive symptomatology. Similarly, recent research shows that individuals with social anxiety disorder have maladaptive beliefs regarding themselves (such as being socially incompetent) and others (as critical judges); when active in a specific social setting, these maladaptive schemes transform innocuous social situations into significant social threats. ${ }^{15,16}$

Young et $\mathrm{al}^{17}$ have used their experience within clinical groups to structure a taxonomy of precocious maladaptive schemes that differentiate for the cognitive content. An early schema is defined as a stable and an enduring pattern, constituted by memories, emotions, knowledge and perception, that concerns oneself and relationships with others. Such schemes would be the result of dissatisfied emotional needs during childhood, elaborated during the whole life and unsuitable in meaningful measure.

Young et $\mathrm{al}^{18}$ distinguish 18 early maladaptive schemes grouped into five domains, which correspond to the frustration of five fundamental psychological infantile needs:

1. Disconnection and rejection: it is typified by the fear of not getting the stability, security and empathy in family relationships, in a consistent or predictable way.
2. Impaired autonomy and performance: this schema domain is typified by expectations about oneself and the personal environment that interfere with one's belief in ability to function independently and one's perceived ability to survive alone, or demonstrate success.

3. Impaired limits: it is characterized by a general lack of internal limits, respect and responsibility to others.

4. Other-directedness: it describes an excessive focus on the wants and needs of others, at the expense of one's own desires.

5. Overvigilance and inhibition: it is typified by an extreme focus on themes of controlling, suppressing or ignoring of spontaneous emotions and impulses.

From this perspective, maladaptive schemes can be described as unsuitable routes coming from repetitive, unfavorable interpersonal relationships with others, which are meaningful during infancy and adolescence. ${ }^{17}$ Because of these disconnected experiences, the fundamental psychological needs are not satisfied, making people vulnerable to the development of environmental management systems. Gradually, these schemes evolve themselves in a precise modality of interaction with oneself and the meaningful others. Moreover, during adulthood, these schemas seem to be different from each other according to the gender; in particular, while adult women seem to manifest a higher level of emotional deprivation, abandonment, mistrust, social isolation, self-sacrifice and negativity/pessimism, ${ }^{19}$ adult men seem to present a higher level of justification of violent beliefs and the impulsivity/carelessness style of problem solving, failure to achieve and dependence on others. ${ }^{20}$

\section{Attachment and cognitive schemes}

Most maladaptive cognitive schemes develop in an individual's lifetime precociously, when the person is relatively impotent and dependent on their caregiver. ${ }^{21}$

Bowlby has hypothesized that, during infancy, individuals internalize one's models of repeated interactions with their caregiver, through the establishment of complex models, called internal working models (IWMs), which serve as a cognitive map for the management of interpersonal relationships. ${ }^{21-23}$ In his attachment theory, Bowlby ${ }^{24-26}$ identifies two IWMs, different but complementary: a model about oneself and a model about others. The first one reflects perceptions about lovableness and acceptance of the attachment figure; the second one refers to the expectations about the availability of one's own caregiver and their reactivity during periods of stress. Both working models constitute the base 
of the attachment behavioral system, a motivational system projected to regulate proximity with the attachment figure. ${ }^{27}$

Working models about oneself and about others are mutable during the first phases of development, but once consolidated, they become relatively firm in lifetime ${ }^{28-30}$ and they direct the interpersonal future behavior in adult age. ${ }^{31,32}$ Besides, such models represent, at least partly, the base of the beliefs of self-efficacy; they influence the modality of emotional regulation, the concept of oneself and the behavioral strategies for the management of uneasiness. ${ }^{33-35}$ Bowlby's ${ }^{21}$ model underlines that early attachment experiences are generalized and summarized in sociorelational schemes, which will influence the future relationships during adulthood. ${ }^{36-38}$

Consistent with this line of research, recent literature has underlined the role of precocious interpersonal experiences in the development of cognitive vulnerability. ${ }^{39-41}$ For example, the precocious attachment interruptions, such as separation from one's own parents, loss or dereliction, could determine the development of adverse cognitive schemes about oneself and/or of others. Therefore, interruptions in early family relationships, the inadequacy of parents, early exposition to interpersonal trauma ${ }^{42}$ but above all dysfunctional parenting (characterized by overprotection) are potential evolutionary precursors to maladaptive cognitive schemes. ${ }^{40,43,44}$ In particular, the literature has shown that subjects with worried attachment manifest higher scores in the schemes that belong to rejection, reduced autonomy and other-directedness domains; ${ }^{45}$ subjects with anxious-avoidant attachment have higher scores in the schemes that belong to the five domains identified by Young's model. ${ }^{46-48}$

Moreover, recent research shows that because mothers and fathers establish different bonds with their children, care and control from mothers and fathers might determine different cognitive schemes in men and women. In particular, in the male group, a dysfunctional mother's parenting style, characterized by low care and high control, could influence the rejection domain in the following dimensions: ${ }^{49}$ the sense of deprivation and emotional inhibition with consequent relational dependence, ${ }^{50}$ vulnerability, pessimism and consequent sense of failure; ${ }^{41}$ a dysfunctional fatherly parenting could influence the trend to subjugation and social isolation. ${ }^{51}$

In a different way, in the female group, dysfunctional maternal parenting, typified by low affection and high control could influence the autonomy domain, ${ }^{52}$ and in particular the sense of deprivation and emotional inhibition; instead, an unsuitable fatherly parenting could influence the sense of failure. ${ }^{41}$ According to this theory, the cognitive vulnerability models assume that the individual cognitive styles (that is, the way of interpreting past events and/or to antedate future events), arising from dysfunctional parenting, can lead to vulnerability and emotional disorder, if enabled by conditions of suitable threat. For instance, depressive cognitive styles, derived by insecure attachment, ${ }^{53}$ could involve a cognitive arrangement pattern connected to the meanings of loss, defeat and failure; then, individuals with depressive styles may be at enhanced risk for developing depression following the occurrence of negative life events. ${ }^{27,54,55}$ Otherwise, the cognitive styles linked to anxiety, derived by insecure attachment, ${ }^{31,56}$ are connected to physical symptoms and vulnerability perception and to a perceptive process about an expected future threat; in particular, the model of anxious incumbent vulnerability postulates that the evaluations of a potential threat represent an evolutionary trial that sometimes allows people to avoid disastrous results by undertaking behaviors of suitable coping. ${ }^{57}$

Based on these studies, the current study seeks to assess the relation of retrospective ratings on parental bonding with cognitive patterns in a group of Italian adults. ${ }^{45}$

The research objectives were the following: 1) to analyze the influence of age and education level on cognitive domains; 2) to verify whether being parents and living at home with parents affect both parenting style and cognitive domains; 3 ) to examine how the variables of motherly and fatherly parenting influence the cognitive styles; 4) to investigate the predictable variables for the use of maladaptive cognitive schemes and 5) to measure the age as moderating variable of the relation between parenting styles and cognitive domains in a group of adult men and women.

With reference to the first objective, it is hypothesized that the younger men manifest higher scores in the cognitive domains, and the men with a higher education level manifest lower scores in the domains. ${ }^{40}$

Furthermore, it is hypothesized that being parents influences parenting style and living at home with parents affects both parenting style and cognitive domains. ${ }^{29,43}$

With reference to the third objective, it is hypothesized that dysfunctional maternal parenting influences the sense of deprivation and emotional inhibition with consequent relational dependence, ${ }^{50}$ pessimism and consequent sense of failure ${ }^{41}$ and a dysfunctional fatherly parenting influences the trend to subjugation and social isolation, only in males. ${ }^{51}$ Furthermore, it is hypothesized that dysfunctional maternal parenting influences the sense of deprivation and emotional inhibition, instead, an unsuitable fatherly parenting influences the sense of failure, in females. ${ }^{35}$ These hypotheses support the studies according to which maternal parenting is a strong 
predictor of disconnection and rejection domain in both sons and daughters, typified by the fear of not getting the stability, security and empathy in family relationships; ${ }^{58,59}$ and the quality of the father-daughter relationship significantly predicts the impaired autonomy and performance domain in daughters, above all, in Southern European countries. ${ }^{60}$

1. With reference to the fourth objective, it is hypothesized that among the predictive variables of the rejection domain, there is a lower level of affection and a higher maternal control in males. ${ }^{49}$

2. A higher control and a lower maternal care are predictive of the autonomy domain in females. ${ }^{55}$

3. A higher control and care of both parents are predictors of the impaired limits domain.

4. A lower control and a higher affection of parents are predictors of the other-directedness domain. ${ }^{45}$

Finally, it is hypothesized that the age represents a moderating variable of the relation between parenting and cognitive domains.

\section{Materials and methods}

\section{Measures}

The participants completed the Parental Bonding Instrument (PBI) and the Young Schema Questionnaire (YSQ).

The 25-item PBI is a questionnaire divided into two parts (one for the mother and one for the father), which measures the retrospective perception of parental style during childhood (first 16 years). ${ }^{61}$ The tool investigates the parenting style through the following two scales:

1. Nurturance (or care), an example of this scale is the following: "Spoke to me in a warm and friendly voice."

2. Control (or overprotection), an example of this scale is: "Tried to control everything I did."

Based on the combination of these two scales, the authors identify four types of attachment: 1) "affectionate constraint" - typified by a high level of care and overprotection; 2) "optimal parenting" - high care and low protection; 3) "affectionless control" - high protection and low care; and 4 ) "neglectful parenting" - low care and low protection. ${ }^{62}$

Assignment to "high" or "low" categories of domains is based on the following cutoff scores: 27.0 for mother's nurturance, 13.5 for mother's control; 24.0 for father's nurturance and 12.5 for father's control. Scores that are at or above those numbers are considered high, and scores that are below those numbers are considered low; high and low scores on the subscales are determined by median split; so, for example, according to the sample means, if an subject presents a low care score and a high protection score, these scores will correspond to the affectionless control parenting.

In adaptation for Italian population, Picardi et al ${ }^{63}$ report the following estimates of internal consistency: 0.75 for mother's care, 0.84 for mother's control, 0.83 for father's care and 0.88 for father's control. The current study shows that the Cronbach's alpha reliability coefficients are the following: 0.68 for mother's nurturance, 0.83 for mother's control, 0.75 for father's nurturance and 0.78 for father's control.

1. The 232-item YSQ-3 is one of the most commonly used measures of cognitive schemes; it investigates 18 cognitive patterns (or cognitive schemas), grouped into the following five domains. ${ }^{64}$

2. Disconnection and rejection domain: emotional deprivation, abandonment, mistrust or abuse, social isolation and defectiveness or shame; an example item belonging to this domain is the following: "There is no one who really cares about me, who will be available to help me, and whom I can fall back on".

3. Impaired autonomy and performance domain: failure to achieve, dependence on others, vulnerability to harm and relational enmeshment; an example item is the following: "I'm powerless and vulnerable and I can't protect myself".

4. Other-directedness domain: subjugation, self-sacrifice; recognition seeking; an example item belonging to the domain is the following: "I have to adapt my needs to other people's wishes; otherwise they will leave me or attack me".

5. Overvigilance and inhibition domain: emotional inhibition, unrelenting standards, pessimism and punitiveness; an example item is: "I need to have complete control of my feelings otherwise things go completely wrong”.

6. Impaired limits domain: entitlement or superiority and insufficient self-control; an example item belonging to the domain is: "I have no control of myself".

For research purposes, the long form of the Italian version was used. ${ }^{65}$ With reference to the assignment to "high" or "low" categories, any score of three or more is considered meaningful (both single score of schema, that composite score of domain). ${ }^{18}$

In the current study, Cronbach's alpha internal consistency coefficient is determined by a factor analysis between 0.53 and 0.81 , in comparison to the Young's model in which the estimate of internal consistency varies between 0.57 (entitlement schema) and 0.74 (failure schema). 


\section{Sample and procedure}

The research involved 209 adults (118 males and 91 females) living in Sicily (Italy), aged between 20 and 60 years ( $M=$ 37.52; $\mathrm{SD}=11.42)$. In the total sample, $64.5 \%$ are parents and $35.5 \%$ do not have children, $64.3 \%$ live alone and $35.7 \%$ live with their parents.

With reference to the gender variable, the participants were grouped into:

1. A subgroup of 118 males aged between 20 and 60 years $(M=36.51 ; \mathrm{SD}=9.31)$ with the following educational levels: middle school diploma (73.7\%), high school diploma (14.4\%) and bachelor's degree (1.7\%); 10.2\% did not report their education level.

2. A subgroup of 91 females of the same age $(M=38.42 ; \mathrm{SD}$ $=13.63)$, with the following educational levels: middle school diploma (59.3\%), high school diploma (20.9\%) and bachelor's degree (15.4\%); $4.4 \%$ did not report their education level.

The sample was obtained with a snowballing sampling design; people were approached through advertising or with direct contact among students of "Kore" University of Enna, and they were asked to help identify other subjects. Participation was secured through written informed consent. The questionnaires were anonymous and the participants were informed of the research aim. The research lasted for 6 months.

The participation in research was not paid, and all participants could withdraw from the study at any time.

The internal review board (IRB) of Faculty of Human and Social Sciences at the "Kore" University of Enna approved the study.

\section{Data analysis}

SPSS for Windows version 23.0 was used.

With reference to the preliminary data, percentage frequency distribution (or descriptive statistic) was used to value the parenting style and cognitive schemas in all groups; Student's $t$-test for independent samples was used to compare the mean scores of parenting styles and cognitive schemes in all participants (males vs females).

With reference to the first research objective, a multivariate analysis of variance (MANOVA) was conducted to analyze the influence of age and education level (sociodemographic variables) on cognitive domains.

Another MANOVA was carried out to verify the second objective, that is, whether being parents and living at home with parents (sociodemographic variables) affect both parenting style and cognitive domains.
With reference to the third research objective, two MANOVAs were used to measure the influence of parenting on cognitive schemas in adulthood (one for male group and one for female group).

Multiple regression analyses were used to investigate the predictable variables for the use of maladaptive cognitive schemes (dependent variables), by including in the model the following independent variables, gender and maternal and paternal parenting. The use of this model has been confirmed by Young et al, ${ }^{17}$ who showed the influence of parents in the development of the early maladaptive schemas and not vice versa.

Since the sample ranged in age between 20 and 60 years, to measure whether the age variable moderates the relation between parenting styles and cognitive domains (the last research objective), moderation analysis was carried out, following the Baron and Kenny ${ }^{66}$ approach.

\section{Results}

A percentage frequency distribution was conducted to investigate the mother's parenting. The results show that $35.6 \%$ of males and $28.6 \%$ of females had an affectionless control attachment (low nurturance and high control); $33.1 \%$ of males and $31.9 \%$ of females presented an optimal parenting (high care and low protection); $16 \%$ of males and $26.4 \%$ of females manifested an affectionate constraint (high scores in both scales) and $15.3 \%$ of males and $13.1 \%$ of females had a neglectful parenting (low care and low protection). The same data analysis was conducted on the father's parenting; results show that $39 \%$ of males and $30.8 \%$ of females manifested optimal parenting; $30.5 \%$ of males and $22 \%$ of females had a neglectful parenting; $25.4 \%$ of males and $22 \%$ of females presented an affectionless control parenting and only 5.1\% of males and $25.2 \%$ of females had an affectionate constraint parenting.

Student's $t$-test for independent samples was used to compare the parenting style and the cognitive schemes between subgroups (males vs females). The first analysis (Table 1) shows that the females report average scores significantly higher than the males in the level of paternal nurturance $(t$ [201.78] $=2.54, p<0.05$ ).

The second analysis (Table 2) shows that the males report average scores significantly higher than the females in impaired autonomy $(t[176.34]=21.93, p<0.05)$; in males, this schema has higher scores than cutoff scores (male: $M=$ 4.26; cutoff score: $M=3.00$ ), then men are considered individuals at risk of manifestation of failure to achieve, dependence on others, vulnerability to harm or relational enmeshment. 
Table I Mean and SD of PBI

\begin{tabular}{llllll}
\hline Scales & \multicolumn{2}{l}{ Males } & & \multicolumn{2}{l}{ Females } \\
\cline { 2 - 3 } \cline { 6 - 7 } & $\mathbf{M}$ & SD & & M & SD \\
\hline Maternal nurturance & 24.71 & 6.29 & & 25.78 & 6.29 \\
Maternal control & 17.06 & 7.18 & & 16.18 & 6.91 \\
Paternal nurturance & 20.76 & 9.19 & & 23.96 & 8.05 \\
Paternal control & 13.18 & 7.66 & & 13.64 & 6.35 \\
\hline
\end{tabular}

Note: Assignment to "high" or "low" categories of domains is based on the following cutoff scores: 27.0 for mother's nurturance, 13.5 for mother's control; 24.0 for father' nurturance, 12.5 for father's control.

Abbreviations: PBI, Parental Bonding Instrument; SD, standard deviation; $M$, mean.

Table 2 Mean and SD of YSQ and cutoff scores

\begin{tabular}{lllllll}
\hline Scales & \multicolumn{2}{l}{ Males } & & \multicolumn{2}{l}{ Females } & \multirow{2}{*}{ Cutoff scores } \\
\cline { 2 - 3 } & $\mathbf{M}$ & SD & & $M$ & SD & \\
\hline Rejection & 2.176 & 0.6485 & & 2.296 & 0.7018 & 3 \\
Impaired autonomy & 4.259 & 0.6220 & & 2.205 & 0.7307 & 3 \\
Other-directedness & 2.532 & 0.6214 & 2.792 & 0.7913 & 3 \\
Overvigilance & $2.78 I$ & 0.8210 & 2.876 & 0.7759 & 3 \\
Impaired limit & 2.641 & 0.8334 & 2.707 & 0.8044 & 3 \\
\hline
\end{tabular}

Notes: The research involved 209 adults (1 18 males and 91 females) living in Sicily (Italy), aged between 20 and 60 years $(M=37.52$; SD $=11.42)$. The assignment to "high" or "low" categories of domains is based on the cutoff score of 3 or more (both the score of each schema and the score of each domain).

Abbreviations: YSQ, Young Schema Questionnaire; SD, standard deviation; $M$, mean.

\section{The influence of sociodemographic variables on cognitive domains and parenting style}

With reference to the first hypothesis, in the male subgroup, MANOVA underlines a main effect linked to the age (Wilks' lambda $=2.63 ; p<0.001$ ), and the education level (Wilks' lambda $=4.95 ; p<0.001)$ on cognitive schemes. The breakdown of the univariate shows that age seems to influence all schemes except enmeshment, self-sacrifice, unrelenting standards and punitiveness; otherwise, the level of education seems to influence only social isolation, vulnerability and emotional inhibition. The analysis of average scores shows that the younger men seem to have higher scores in the following domains: abandonment, fear of being exploited, inadequacy, failure, dependence upon others, subjection, dependence judgment, emotional inhibition, pessimism and self-control; the older ones seem to manifest higher scores in social isolation, vulnerability and entitlement. With reference to the educational level, Tukey's post hoc test shows that men with a higher education level show greater sense of isolation and emotional control, but a lower level of fear of illness (Table 3).

In the female subgroup, MANOVA emphasizes the effect linked to education level (Wilks' lambda $=1.13 ; p<0.05$ ) on the abandonment domain; Tukey's post hoc test shows that
Table 3 The breakdown of the univariate effects with respect to the age and education variables in the male group

\begin{tabular}{lll}
\hline Measures & Age & Education level \\
\cline { 2 - 3 } & $\mathbf{F}$ & $\boldsymbol{F}$ \\
\hline Emotional deprivation & $3.18^{* * *}$ & 0.38 \\
Abandonment & $4.19^{* * *}$ & 2.28 \\
Mistrust & $2.57^{* *}$ & 0.64 \\
Social isolation & $3.27^{* * *}$ & $3.27^{*}$ \\
Defectiveness & $3.43^{* * *}$ & 2.05 \\
Failure & $4.36^{* * *}$ & 0.35 \\
Dependence & $6.94^{* * *}$ & 0.82 \\
Vulnerability & $2.60^{* *}$ & $3.15^{*}$ \\
Enmeshment & 0.85 & 1.61 \\
Subjugation & $2.82^{* * *}$ & 1.31 \\
Self-sacrifice & 1.30 & 2.09 \\
Recognition seeking & $2.34^{* *}$ & 0.69 \\
Emotional inhibition & $2.89^{* * *}$ & $3.89^{*}$ \\
Unrelenting standards & 1.12 & 0.89 \\
Pessimism & $2.45^{* *}$ & 1.47 \\
Punitiveness & 1.56 & 0.66 \\
Entitlement & $2.47^{* *}$ & 0.52 \\
Insufficient self-control & $2.81^{* * *}$ & 1.17 \\
\hline Notes &
\end{tabular}

Notes: ${ }^{* * *} p<0.001$, two-tailed; $* * p<0.01$, two-tailed, ${ }^{*} p<0.05$, two-tailed.

women with a higher education level show a lower level of abandonment fear.

With reference to the second hypothesis, a subsequent MANOVA was carried out to verify whether being parents and living at home with parents affect parenting and cognitive domains. The analysis shows no significant effect $(p>0.05)$.

\section{Effects of parenting style on cognitive schema}

In the male group, MANOVA underlines the influence of the level of motherly (Wilks' lambda $=9.69 ; p<0.001$ ) and fatherly parenting style (Wilks' lambda $=6.68 ; p<0.001$ ) and the effect of interaction paternal $\times$ maternal parenting (Wilks' lambda $=6.00 ; p<0.001)$ on the majority of the cognitive schemas. The first breakdown of the univariate effects shows that the type of maternal parenting affects all domains except social isolation and subjugation (Table 4). Tukey's post hoc test underlines that men with affectionate constraint maternal parenting manifest a higher level of mistrust, enmeshment, subjugation, self-sacrifice, recognition seeking, pessimism and insufficient self-control; men with affectionless control parenting manifest a higher level of emotional deprivation, defectiveness, failure, dependence, vulnerability and unrelenting standards.

With reference to the influence of paternal parenting, Tukey's post hoc test underlines that men with affectionate constraint parenting manifest a high level of emotional 
Table 4 The breakdown of the univariate effects with respect to the maternal and paternal parenting in the male group

\begin{tabular}{|c|c|c|c|}
\hline \multirow[t]{2}{*}{ Measures } & & $\begin{array}{l}\text { Maternal } \\
\text { parenting }\end{array}$ & \multirow{2}{*}{$\begin{array}{l}\text { Paternal } \\
\text { parenting } \\
F \\
\end{array}$} \\
\hline & $d f(3, I I 4)$ & $\boldsymbol{F}$ & \\
\hline Emotional deprivation & & $8.62 * * *$ & $4.50 * *$ \\
\hline Abandonment & & $3.11 *$ & 0.85 \\
\hline Mistrust & & $19.44^{* * *}$ & 1.71 \\
\hline Social isolation & & 0.39 & $3.28 *$ \\
\hline Defectiveness & & $3.64^{*}$ & 1.25 \\
\hline Failure & & $2.77^{*}$ & 0.57 \\
\hline Dependence & & $4.21^{* *}$ & 1.74 \\
\hline Vulnerability & & $8.87^{* * *}$ & 0.93 \\
\hline Enmeshment & & $10.88^{* * *}$ & $11.50 * * *$ \\
\hline Subjugation & & 2.54 & $9.70 * * *$ \\
\hline Self sacrifice & & $2.87^{*}$ & $7.76 * * *$ \\
\hline Recognition seeking & & $7.02 * * *$ & $3.28^{*}$ \\
\hline Emotional inhibition & & $4.8 I^{* * *}$ & 0.22 \\
\hline Unrelenting standards & & $9.36 * * *$ & $4.62^{* *}$ \\
\hline Pessimism & & $8.60^{* * * *}$ & 0.34 \\
\hline Punitiveness & & $6.17^{* * *}$ & $2.75^{*}$ \\
\hline Entitlement & & $9.76 * * *$ & I.7I \\
\hline Insufficient self-control & & $3.39 *$ & 0.98 \\
\hline
\end{tabular}

Note: $* * * p<0.001$, two-tailed; $* * p<0.01$, two-tailed, ${ }^{*} p<0.05$, two-tailed.

deprivation; individuals with neglectful paternal parenting show a high social isolation and sense of failure; men with affectionless control paternal parenting present a high level of enmeshment and subjects with optimal paternal parenting manifest a high level of subjugation, self-sacrifice and unrelenting standards.

With reference to the interaction effect between paternal and maternal parenting, the analysis of the average scores shows that men with affectionate constraint maternal parenting and neglectful paternal parenting manifest a higher level of emotional deprivation and pessimism; men with neglectful parenting (maternal and paternal) manifest a higher level of social isolation; men with affectionate constraint maternal parenting and affectionless control paternal parenting present a higher level of self-sacrifice and unrelenting standards; adult men with parenting characterized by neglectful maternal and optimal paternal attachment manifest a higher level of vulnerability and sense of failure; finally, men with affectionless control maternal parenting and optimal paternal parenting seem to present a higher sense of abandonment (Table 4).

In the female group, MANOVA underlines only the influence of the mother's parenting style (Wilks' lambda = 2.367; $p<0.05$ ) on emotional deprivation and sense of failure (Table 5). Tukey's post hoc test underlines that women with affectionless control parenting manifest higher level of emotional deprivation and failure (Table 5).
Table 5 The breakdown of the univariate effects with respect to the maternal and paternal parenting in the female group

\begin{tabular}{|c|c|c|c|}
\hline \multirow[t]{2}{*}{ Measures } & \multirow[b]{2}{*}{$d f(3,87)$} & \multirow{2}{*}{$\begin{array}{l}\text { Maternal } \\
\text { parenting } \\
\boldsymbol{F} \\
\end{array}$} & \multirow{2}{*}{$\begin{array}{l}\text { Paternal } \\
\text { parenting }\end{array}$} \\
\hline & & & \\
\hline Emotional deprivation & & $5.03 * *$ & 1.73 \\
\hline Abandonment & & 1.75 & 0.45 \\
\hline Mistrust & & 0.79 & 0.27 \\
\hline Social isolation & & 0.99 & 1.38 \\
\hline Defectiveness & & 1.10 & 0.63 \\
\hline Failure & & $2.83 *$ & 0.14 \\
\hline Dependence & & 0.89 & 0.63 \\
\hline Vulnerability & & 2.03 & 0.39 \\
\hline Enmeshment & & 1.28 & 0.97 \\
\hline Subjugation & & 0.31 & 0.30 \\
\hline Self-sacrifice & & 0.20 & 2.10 \\
\hline Recognition seeking & & 1.53 & 0.35 \\
\hline Emotional inhibition & & 0.37 & 0.42 \\
\hline Unrelenting standards & & 1.35 & 0.24 \\
\hline Pessimism & & 1.63 & 0.23 \\
\hline Punitiveness & & 0.73 & 0.39 \\
\hline Entitlement & & 2.11 & 1.16 \\
\hline Insufficient self-control & & 0.26 & 0.21 \\
\hline
\end{tabular}

Notes: $* * p<0.01$, two-tailed; $* p<0.05$, two-tailed.

\section{Predictive variables of cognitive schema}

With reference to predictive variables of cognitive domains, the first regression analysis shows that being a male $(\beta=$ $-0.16 ; p<0.05)$, at a younger age $(\beta=-0.23 ; p<0.01)$ and, above all, with a lower level of mother's nurturance $(\beta$ $=-0.30 ; p<0.001)$ seem to be predictors of the rejection domain ( $19 \%$ of the overall variance explained).

Furthermore, being a male, at a younger age, with a lower level of mother's care represents predictor of the impaired autonomy domain (Table 6).

Being a male $(\beta=0.15, p<0.05)$ with a higher level of paternal care $(\beta=0.24, p<0.001)$ is the only predictive variable of the other-directedness domain $(8.8 \%$ of total variance). The younger age $(\beta=-0.23, p<0.01)$ and a higher mother's control $(\beta=0.15, p<0.05)$ are the only predictive variables of the overvigilance domain $(11.2 \%$ of total variance). Similarly, the younger age $(\beta=-0.27, p<0.001)$, with a higher level of maternal control $(\beta=0.17, p<0.05)$, is the predictor of the impaired limits domain, explaining $11.1 \%$ of the total variance.

Due to the pattern of correlation found in the current study that age variable appears to explain variance of cognitive domains, there is justification in exploring age variable as a possible moderator of the relationship between parenting style and cognitive domains. The moderation analyses were conducted following the Baron and Kenny's procedure. With regard to the maternal parenting, the first shows that 
Table 6 Summary of the linear regression analyses predicting the Impaired Autonomy domain

\begin{tabular}{llllll}
\hline Variable & $\boldsymbol{R}^{2}$ & Adjusted $\boldsymbol{R}^{2}$ & $\mathbf{S E}$ & $\boldsymbol{\beta}$ & $\mathbf{T}$ \\
\hline Gender & 0.73 & 0.72 & 0.10 & -0.82 & $-20.88^{* * * *}$ \\
Age & & & 0.00 & -0.13 & $-3.31^{* * *}$ \\
Education level & & & 0.07 & 0.02 & 0.46 \\
Mother's nurturance & & & 0.01 & -0.09 & $-1.80^{*}$ \\
Mother's control & & & 0.01 & 0.07 & 1.57 \\
Father's nurturance & & & 0.01 & 0.01 & 0.23 \\
Father's control & & & 0.01 & 0.01 & 0.11 \\
\hline
\end{tabular}

Notes: ${ }^{* * *} p<0.001$, two-tailed; $* p<0.05$, two-tailed.

age moderates the correlation between maternal nurturance and the impaired autonomy and performance domain $(\beta=$ $0.14, p<0.05)$. The second underlines that age moderates the correlation between maternal control and the impaired limits domain $(\beta=0.16, p<0.05)$.

With regard to the paternal parenting style, the first moderation analysis shows that age moderates the correlation between paternal nurturance and the rejection domain $(\beta=$ $0.21, p<0.01$ ). The second shows that age moderates the relation between paternal nurturance and the impaired autonomy domain $(\beta=0.15, p<0.05)$. The third analysis shows that age moderates the correlation between paternal nurturance and the domain of impaired limits $(\beta=0.22, p<0.01)$.

\section{Discussion}

Objectives of the current research were the following: to analyze the influence of age and education level on cognitive domains; to verify whether being parents and living at home with parents affect both parenting style and cognitive domains; to assess how maternal and paternal parenting independently influence cognitive domains in a group of adult men and women; to investigate the predictive variables using dysfunctional domains and to investigate the age as moderating variable of the relation between parenting and cognitive domains.

According to the first hypothesis, the younger men seem to manifest a higher level of abandonment, sense of inadequacy, failure and consequently pessimism, to which are added fear of being exploited, subjection and accordingly, emotional inhibition; furthermore, men with a higher level of education level show a lower level of fear of illness; similarly, women with a higher education level show a lower level of abandonment fear.

The second research hypothesis does not appear to be confirmed, because being parents and living at home with parents do not seem to affect parenting and cognitive domains; a possible explanation for this finding is that, in the Sicilian family, the strong bonds between parents and children remain even when children - who have become adults - constitute a new independent household.

According to the third hypothesis, the results underline that men with maternal parenting characterized by affectionate constraint seem to manifest a higher level of mistrust, enmeshment, subjugation, self-sacrifice, recognition seeking, pessimism and insufficient self-control; furthermore, in the male group, affectionless control parenting appears to influence the relational ability, characterized by the perception of emotional deprivation, which leads them to implement the defense mechanism of relational addiction and the dysfunctional perception of self characterized by vulnerability, defectiveness and consequently sense of failure. With reference to paternal parenting, men with attachment characterized by affectionate constraint seem to manifest a higher level of emotional deprivation; individuals with neglectful parenting show social isolation and sense of failure and men with affectionless control parenting present enmeshment. These outcomes confirm the literature that underlines the role of paternal support for adolescent and adult males in specific domains, such as social isolation and aggression. ${ }^{52}$

It is interesting how men with optimal paternal parenting manifest a higher level of self-sacrifice, subjugation and unrelenting standards. This finding could be explained by the fact that in Sicilian culture, roles within the family are strongly emphasized, and individuals have an extreme need to meet parental and social expectations. ${ }^{67-69}$ This process, which is very common among Southern Italians, to make a good impression (fare bella figura) when interacting with other people, is very much a matter of showing integrity and bringing people to have respect for them; when they are not able to adopt to social pressure - that is, when they make a "bad impression" - people therefore feel shame. So, exposure to perfectionism and to an authoritarian parenting style may bring the individual to the perception of rigorous expectations, self-esteem linked to success and fear of disappointing others. ${ }^{44,70}$ With reference to the female group, it is interesting that affectionless control parenting between women and their mothers seems to affect the representation that the subject has of herself, in terms of failure and emotional privation. These results confirm that maternal support may be more important for daughters in some specific domains, such as self-efficacy and the perception of themselves as lovable subjects. ${ }^{71}$ Why paternal dimensions did not influence the cognitive schemes for female result is unclear. One possibility is that the mother's parenting style is more influential in females, because Sicilian mothers typically spend more time with their children. In addition, the literature underlines that females report higher 
disclosure with mothers than with fathers, and this element may influence their social competence and self-esteem.

In fact, Italy, as we know it today, has been described as at least two areas, the North and the South, divided by three important factors: the significance attributed to the family as a social unit, the ubiquitous strength of kinship ties with the independent family structure and the different role between parents, characterized by the strong presence of the mother. ${ }^{72}$ Consider, in particular, the paradigm of "amoral familism" in Sicily, which created by Banfield ${ }^{73}$ in the attempt to figure out why some communities are socially and economically backward; the author suggested that certain communities would be set back especially for cultural reasons. Their culture would present an extremist conception of family bonds which harms both the ability to associate and the collective interest. Individuals seem to act according to the following rule: maximizing only the benefits of short-term materials of their own nuclear family, assuming that everyone else will behave likewise. It would therefore be this particular ethics of family relationships to be the cause of Sicilian backwardness, which the author called amoral familism; familism because the individual would pursue only the interests of their nuclear family, and never that of the community that requires cooperation among unrelated individuals; amoral because following the rule it applies categories of good and evil only among family members, and not toward other members of the community.

Our study shows that being a younger adult male with maternal parenting characterized by reduced care is a predictor of the tendency to expect that own needs for stability and security in family relationships will not be made, and of the tendency to relational enmeshment, and, consequently, to depend on others.

Moreover, being a male with a higher paternal nurturance is predictive of the tendency to other-directedness and correlates to an extreme attention to the needs of others, although in a functional manner. As confirmed by the international literature, father's involvement may be an important predictor for independence, internal locus of control and need for achievement, so paternal care or nurturance may influence relational adjustment in preventing antisocial behavior. The literature, in fact, underlines that the relation between attachment anxiety and psychopathology is mediated by cognitive schemes regarding rejection, disconnection and other-directedness. ${ }^{74}$

The younger age and a higher mother's control are predictors of the overvigilance domain, which may lead individuals to manifest emotional inhibition, unrelenting standards and pessimism; they are also predictors of the impaired limits domain, because excessive control is hypothesized to have its negative influence on psychosocial competence, not only because it damages the parent-child relationship but, above all, because it is often accompanied by maladaptive effects such as the sense of personal control.

Since the data analyses showed significant relationships between age, parenting styles and cognitive domains, we examined moderation models of age variable. The results indicated that age moderates only the correlation between maternal nurturance and the domain of impaired autonomy, maternal control and the domain of impaired limits; in addition to this, age moderates the relation between paternal nurturance with rejection domain, impaired autonomy and impaired limits domains. So, age seems to moderate the relationship between maternal parenting and schemes partially, but does not appear to moderate the relationship between parental control and schemes.

These results confirm Young's model that underlines that the loss of autonomy and elevated protection lead to the development of maladaptive schemas, underlining the influence of the family in the development of such schemas. The presence of dysfunctional cognitive schemes, and overall psychological distress, therefore, must always be investigated in the singularity and individuality, relating to the individual, rather than disease or discomfort, through dialog, exchange and listening. ${ }^{75}$

\section{Conclusion}

Few research studies have measured the influence of mother's and father's parenting styles on adult outcomes, supporting the hypothesis that mother's and father's attachment influences different domains of personal and interpersonal adaptation.

Although both dimensions of parenting, care and control, appear to be relevant, few researches have assessed these parenting styles and only a small part of the literature has valued the influence of the father and the effect that the lack of his support has on children's cognitive schemes when they become adults; in fact, although parental bonding has been extensively investigated as a predictor of psychiatric outcomes, less is known about its association with schemata underlying these outcomes.

It is important to underline that maternal care interacts with paternal care in predicting cognitive schemes in adult sons. These outcomes suggest that mother's support can serve as a protective variable in the development of dysfunctional cognitive schemes, protecting a child from an unsupportive relationship with a father.

The current research had some limitations that need to be considered. First of all, the research values the relationship between parental style and cognitive domains in a group of adults; so, as is indubitably the case in all correlation studies, the results in no way allow for casual conjectures. 
We did not use a measure to account for socially desirable responding and/or the tendency to minimize pathology; furthermore, we did utilize retrospective ratings to measure parental bonding and not use actual parental behaviors.

Another limitation was the small sample size that may have limited the generalizability of our findings and the ability to identify other differences in maladaptive schemas.

Furthermore, since the results suggest that parenting drives adult cognitive schemes, however, these models account for $<20 \%$ of the variance in the dependent variable (except for impaired autonomy); probably there are other factors that may be playing a role in cognitive schemes, such as, adult life stress and current relationship status/satisfaction, which could be investigated in a future study.

In general, parental insensitivity is able to disrupt the ability of individuals to adjust their behavior and emotions. ${ }^{76}$ The family can be as much an element of risk as a protective factor against mental distress and psychopathology outcomes in the individual. Family relationships can be important protective factors, such as appropriate emotional tuning and high flexibility of roles. A good satisfaction of the members of a family can reduce the risk of development and maintenance of dysfunctional behavior in adolescence, which are consolidated as cognitive dysfunctional schemes in adulthood.

\section{Disclosure}

The authors report no conflicts of interest in this work.

\section{References}

1. Beck AT, Freeman A, Pretzer J, et al. Cognitive Therapy of personality disorders. New York: Guilford Press; 1990.

2. Pellerone M, Craparo G, Tornabuoni Y. Relationship between parenting and cognitive schemas in a group of male adult offenders. Front Psychol. 2016;7:302.

3. Craparo G, Gori A, Mazzola E, Petruccelli I, Pellerone M, Rotondo G. Posttraumatic stress symptoms, dissociation, and alexithymia in an Italian sample of flood victims. Neuropsychiatr Dis Treat. 2014;10:2281-2284.

4. Formica I, Barbàra F, Trotta A. The association between alexithymia and impoverishment of dreaming: an empirical research amongst undergraduate students. Mediterr J Clin Psychol. 2013;2(1).

5. Trotta A, Di Forti M, Mondelli V, et al. Prevalence of bullying victimisation amongst first-episode psychosis patients and unaffected controls. Schizophr Res. 2013;150(1):169-175.

6. Friedman ES, Thase ME. Cognitive-behavioral therapy for depression and dysthymia. In: Stein DJ, Kupfer DJ, Schatzberg AF, editors. Mood Disorders. Washington: American Psychiatric Publishing; 2006:353-371.

7. Friedman ES, Thase ME, Wright JH. Cognitive and behavioral therapies. In: Tasman A, Kay J, Lieberman JA, First MB, Maj M, editors. Psychiatry. Chichester: Wiley-Blackwell; 2008:1920-1947.

8. Mannino G, Giunta S. Psychodynamics of the mafia phenomenon: psychological - clinical research on environmental tapping and whitecollar crime. World Futures. 2015;71:185-201.

9. Subbe D, Zeanah CH, Mrazek DA. A psychiatric perspective on Human development. In: Tasman A, Kay J, Lieberman A, First MB, Riba M, editors. Psychiatry. Vol. 2. New York: Wiley, Blackwell; 2015:101-121.
10. Di Maria F, Formica I. L'autoreferenzialità in psicologia clinica e in psicoterapia [Self-referentiality in clinical psychology and psychotherapy]. Riv Psicol Clin. 2009;2:72-79.

11. Beck AT, Freeman A, Associates. Cognitive Therapy of Personality Disorders. New York: Guilford Press; 1990.

12. Christensen BK, Carney CE, Segal ZV. Cognitive processing model of depression. In: Stein DJ, Kupfer DJ, Schatzberg AF, editors. The American Psychiatric Publishing Textbook of Mood Disorders. Washington, DC: American psychiatric publishing; 2006:131-144.

13. Young J, Weinberg A, Beck A. Cognitive therapy for depression. In: Barlow D, editor. Clinical Handbook of Psychological Disorders. 3rd ed. New York: Guilford; 2001:264-308.

14. Beck AT. Depression: Causes and Treatment. Philadelphia: University of Pennsylvania Press; 1972.

15. Heimberg RG, Brozovich FA, Rapee RM. A cognitive-behavioral model of social anxiety disorder: update and extension. In: Hofmann SG, DiBartolo PM, editors. Social Anxiety: Clinical, Developmental, and Social Perspectives. New York: Academic Press; 2010:395-422.

16. Boden MT, John OP, Goldin PR, Werner K, Heimber RG, Gross JJ. The role of maladaptive beliefs in cognitive-behavioral therapy: evidence from social anxiety disorder. Behav Res Ther. 2012;50(5):287-291.

17. Young JE, Klosko JS, Weishaar M. Schema Therapy: A practitioner's Guide. New York: Guilford Press; 2003.

18. Young JE, Klosko JS, Weishaar ME. Schema Therapy: La terapia cognitivo comportamentale per i disturbi di personalità [Schema Therapy: Cognitive Behavioral Therapy for Personality Disorders]. Firenze: Eclipsi; 2007.

19. Shorey RC, Anderson SE, Stuart GL. Gender differences in early maladaptive schemas in a treatment-seeking sample of alcohol-dependent adults. Subst Use Misuse. 2012;47(1):108-116.

20. Calvete E, Cardeñoso OJ. Gender differences in cognitive vulnerability to depression and behavior problems in adolescents. Abnorm Child Psychol. 2005;33:179-192.

21. Bowlby J. The role of attachment in personality development. In: Bowlby J, editor. Parent Child Attachment and Human Health Development. London: Routledge; 1988:240-294.

22. Pellerone M. Time perception in children with developmental dyscalculia. Proc Soc Behav Sci. 2013;103:1220-1227.

23. Pellerone M. Influence of identity, congruence of interest and coping strategy on decision making. Proc Soc Behav Sci. 2015;191:1344-1348.

24. Bowlby J. Attachment and Loss: Vol. 1. Attachment. New York: Basic Books; 1969.

25. Bowlby J. Attachment and Loss: Vol. 2. Separation, Anxiety and Anger. New York: Basic Books; 1973.

26. Bowlby J. Attachment and Loss: Vol. 3. Sadness and Depression. New York: Basic Books; 1980.

27. Williams NL, Riskind JH. Adult romantic attachment and cognitive vulnerabilities to anxiety and depression: examining the interpersonal basis of vulnerability models. J Cogn Psychother. 2004;18:7-24.

28. Fraley RC, Waller NG, Brennan KA. An item response theory analysis of self-report measures of adult attachment. J Pers Soc Psychol. 2000;78(2):350-365.

29. Sroufe LA, Waters E. Attachment as an organizational construct. Child Dev. 1977;48:1184-1199.

30. Weinferld NS, Sroufe LA, Egeland B. Attachment from infancy to early adulthood in a high-risk sample: continuity, discontinuity and their correlates. Child Dev. 2000;71(3):695-700.

31. Hazan C, Shaver PR. Romantic love conceptualized as an attachment process. J Pers Soc Psychol. 1987;52(3):511-524.

32. Pellerone M, Passanisi A, Bellomo M. Identity development, intelligence structure, and interests: a cross-sectional study in a group of Italian adolescents during the decision-making process. Psychol Res Behav Manag. 2015;8:239-249.

33. Gullo S, Lo Coco G, Di Fratello C, et al. Group climate, cohesion, and curative climate: a study on the common factors in the group process and their relation with members' attachment dimensions. Res Psychother. 2015;18:10-20.

34. Mikulincer M. Adult attachment style and affect regulation: strategic variations in self-appraisals. J Pers Soc Psychol. 1998;75(2):420-435. 
35. Mikulincer M, Arad D. Attachment, working models, and cognitive openness in close relationships: a test of chronic and temporary accessibility effects. J Pers Soc Psychol. 1999;77:710-725.

36. Bellomo MFP, Pellerone M. The role of emotional regulation, self-efficacy, heuristics and risk appetite on financial decision-making process. A study on groups of senior and junior investors. Am Int J Soc Sci. 2015;4(5):169-175.

37. Lee SJ, Cloninger CR, Park SH, Chae H. The association of parental temperament and character on their children's behavior problems. Peer J. 2015;3:e1464.

38. Iacolino C, Pellerone M, Pace U, Ramaci T, Castorina V. Family functioning and disability: a study on Italian parents of disabled children. Eur Proc Soc Behav Sci. 2016;8:39-52.

39. Alloy LB. The developmental origins of cognitive vulnerability to depression: negative interpersonal context leads to personal vulnerability. Cognit Ther Res. 2001;25:349-352.

40. Alloy LB, Abramson LY, Tashman NA, et al. Developmental origins of cognitive vulnerability to depression: parenting, cognitive, and inferential feedback styles of the parents of individuals at high and low cognitive risk for depression. Cognit Ther Res. 2001;25:397-424.

41. Mikulincer M, Shaver PR. An attachment perspective on psychopathology. World Psychiatry. 2012;11(1):11-15.

42. Mannino G, Giunta S, Buccafusca S, Cannizzaro G, Lo Verso G. Communication strategies in Cosa Nostra: an empirical research. World Futures. 2015;71:153-172.

43. Chorpita BF, Barlow DH. The development of anxiety: the role of control in the early environment. Psychol Bull. 1998;124(1):3-21.

44. Pellerone M, Tolini G, Polopoli C. Parenting, identity development, internalizing symptoms and alcohol use. A cross-sectional study in a group of Italian adolescents. Neuropsychiatr Dis Treat. 2016;12:1769-1778.

45. Thimm JC. Early maladaptive schemas and interpersonal problems: a circumplex analysis of the YSQ-SF. Int J Psychol Psychol Ther. 2013;13(1): 113-124.

46. Mason O, Platts H, Tyson M. Early maladaptive schemas and adult attachment in a UK clinical population. Psychol Psychother. 2005;78(pt 4): 549-564.

47. Schmidt NB, Joiner TE, Young JE, Telch MJ. The schema questionnaire: investigation of psychometric properties and the hierarchical structure of a measure of maladaptive schemas. Cognit Ther Res. 1995;19:295-321.

48. Thompson RA. Attachment-related mental representations: introduction to the special issue. Attach Hum Dev. 2008;10(4):347-358.

49. Marta E, Lanz M, Manzi C, Tagliabue S, Pozzi M, Bertoni A. La relazione genitori-adolescenti: un predittore della devianza [The relationship parents-teenagers: a predictor of deviance]. Psicologia clinica dello sviluppo. 2004;2:269-288.

50. Liotti G, Farina B. Sviluppi traumatici: eziopatogenesi, clinica e terapia della dimensione associativa [Traumatic Developments: Etiology, Clinical and Treatment of Associative Dimension]. Milano: Raffaello Cortina; 2011

51. Nakash-Eisikovits O, Dutra L, Westen D. Relationship between attachment patterns and personality pathology in adolescents. J Am Acad Child Adolesc Psychiatry. 2002;41(9):1111-1123.

52. Laible DJ, Carlo G. The differential relations of maternal and paternal support and control to adolescent social competence, self-worth, and sympathy. J Adolesc Res. 2004;19(6):759-782.

53. Davila J, Hammen C, Burge D, Daley SE, Paley B. Cognitive/interpersonal correlates of adult interpersonal problem-solving strategies. Cognit Ther Res. 1996;20:465-480.

54. Craparo G, Gori A, Petruccelli I, Cannella V, Simonelli C. Intimate partner violence: relationships between alexithymia, depression, attachment styles, and coping strategies of battered women. J Sex Med. 2014;11(6):1484-1494.

55. Catanzaro A, Wei M. Adult attachment, dependence, self-criticism, and depressive symptoms: a test of a meditational model. J Pers. 2010;78(4): 1135-1162.
56. Eng W, Heimberg RG, Hart TA, Schneier FR, Liebowitz MR. Attachment in individuals with social anxiety disorder: the relationship among adult attachment styles, social anxiety, and depression. Emotion. 2001; 1(4):365-380.

57. Kleiman EM, Riskind JH. Cognitive vulnerability to comorbidity: looming cognitive style and depressive cognitive style as synergistic Predictors of anxiety and depression symptoms. J Behav Ther Exp Psychiatry. 2012;43(4):1109-1114.

58. Ingram RE. Origins of cognitive vulnerability to depression. Cognit Ther Res. 2003;27/1:77-88.

59. Nia MK, Sovani A, Forooshani GRS. Exploring correlation between perceived parenting styles, early maladaptive schemas, and depression among women with depressive symptoms in Iran and India - role of early maladaptive schemas as mediators and moderatos. Iran Red Crescent Med J. 2014;16(12):e17492.

60. Boyd K, Ashcraft A, Belgrave FZ. Impact of mother-daughter and father-daughter relationships on drug refusal self-efficacy among African American adolescent girls in urban communities. J Black Psychol. 2006;32(1):29-42.

61. Parker G, Tupling H, Brown LB. Parental bonding instrument. Br JMed Psychol. 1979;52:1-10.

62. Parker G. The Parental Bonding Instrument: psychometric properties reviewed. Psychiatr Dev. 1989;7(4):317-335.

63. Picardi A, Tarsitani L, Toni A, et al. Validity and reliability of the Italian version of the Measure of Parental Style (MOPS). J Psychopathol. 2013;19:54-59.

64. Young JE. Young Schema Questionnaire-Short Form 3. New York: Schema Therapy Institute; 2005.

65. Saggino A, Balsamo M, Da Fermo G, et al. Standardizzazione e validazione della versione italiana dello Young Schema Questionnaire, versione L-3 [Standarditation and validation of Italian form of the Schema Questionnaire]. Psicoter Cogn Comport. 2014;20:387-390.

66. Baron RM, Kenny DA. The moderator-mediator variable distinction in social psychological research: conceptual, strategic, and statistical considerations. J Pers Soc Psychol. 1986;51(6):1173-1182.

67. Huckle T, You RQ, Casswell S. Socio-economic status predicts drinking patterns but not alcohol-related consequences independently. Addiction. 2010;105(7):1192-1202.

68. Lemstra M, Bennett NR, Neudorf C, et al. A meta-analysis of marijuana and alcohol use by socio-economic status in adolescents aged 10-15 years. Can J Public Health. 2008;99(3):172-177.

69. Syed M, Seiffge-Krenke I. Personality development from adolescence to emerging adulthood: linking trajectories of ego development to the family context and identity formation. J Pers Soc Psychol. 2013;104(2):371-384

70. Clark DB, Thatcher DL, Maisto SA. Supervisory neglect and adolescent alcohol use disorders: effects on AUD onset and treatment outcome. Addict Behav. 2005;30(9):1737-1750.

71. Park LE, Crocker J, Mickelson KD. Attachment styles and contingencies of self-worth. Pers Soc Psychol Bull. 2004;30(10):1243-1254.

72. Lamb ME. The Father's Role: Cross-cultural Perspectives. New Jersey: Lawrence Erlbaum Associates; 1987.

73. Banfield ES. Familismo amorale. Le basi morali di una società arretrata [Amoral Familism. The Moral Basis of a Backward Society]. Roma: IL Mulino; 2010.

74. Bosmans G, Braet C, Van Vlierberghem L. Attachment and symptoms of psychopathology: early maladaptive schemas as a cognitive link? Clin Psychol Psychother. 2010;17(5):374-385.

75. Formica I. La ricerca empirica in psicoterapia di gruppo: Stato dell'arte e direzioni future [Empirical research in group psychotherapy: current status and future directions]. Narrare i gruppi. 2012;2: 58-72.

76. Coppola E, Formica I. Ndrangheta and The Street: Experiential Group with Reggio Calabria Flying Squad Policemen. World Futures. 2015;71(5-8):214-227. 


\section{Publish your work in this journal}

Psychology Research and Behavior Management is an international, peerreviewed, open access journal focusing on the science of psychology and its application in behavior management to develop improved outcomes in the clinical, educational, sports and business arenas. Specific topics covered in the journal include: Neuroscience, memory and decision making; Behavior modification and management; Clinical applications; Business and sports performance management; Social and developmental studies; Animal studies. The manuscript management system is completely online and includes a very quick and fair peer-review system, which is all easy to use. Visit http://www. dovepress.com/testimonials.php to read real quotes from published authors.

Submit your manuscript here: https://www.dovepress.com/psychology-research-and-behavior-management-journal 